Chapman University

Chapman University Digital Commons

Food Science Faculty Articles and Research

Science and Technology Faculty Articles and

Research

8-31-2018

\title{
Effects of Fruit Position in Standard Place Pack Cartons and Gamma 1 Irradiation on the Postharvest Quality of 'Barnfield' Navel Oranges
}

Karina Cruz Rodriguez (Friscia)

Chapman University

José de Jesús Ornelas-Paz

Unidad Cuauhtémoc

Vrani Ibarra-Junquera

Universidad de Colima

Maria Criselda Toto

Chapman University, toto@chapman.edu

Akanksha Jain

Chapman University, jain118@mail.chapman.edu

See next page for additional authors

Follow this and additional works at: https://digitalcommons.chapman.edu/food_science_articles

Part of the Agricultural Science Commons, Agriculture Commons, Botany Commons, Food Processing Commons, Fruit Science Commons, and the Other Food Science Commons

\section{Recommended Citation}

Rodriguez (Friscia), K.C., Ornelas-Paz, J., Ibarra-Junquera, V. et al. Effects of Fruit Position in Standard Place Pack Cartons and Gamma Irradiation on the Postharvest Quality of 'Barnfield' Navel Oranges. Food Bioprocess Technol (2018). https://doi.org/ $10.1007 / \mathrm{s} 11947-018-2174-6$ 


\section{Effects of Fruit Position in Standard Place Pack Cartons and Gamma 1 Irradiation on the Postharvest Quality of 'Barnfield' Navel Oranges}

\section{Comments}

This is a pre-copy-editing, author-produced PDF of an article accepted for publication in Food and Bioprocess Technology in 2018 following peer review. The final publication is available at Springer via DOI: 10.1007/ s11947-018-2174-6.

\section{Copyright}

Springer

\section{Authors}

Karina Cruz Rodriguez (Friscia), José de Jesús Ornelas-Paz, Vrani Ibarra-Junquera, Maria Criselda Toto, Akanksha Jain, and Anuradha Prakash 

Irradiation on the Postharvest Quality of 'Barnfield' Navel Oranges

4 Karina Cruz Rodriguez (Friscia) ${ }^{1}$, José de Jesús Ornelas-Paz ${ }^{2, *}$, Vrani Ibarra-

5 Junquera ${ }^{3}$, Maria Criselda Toto ${ }^{1}$, Akanksha Jain $^{1}$, Anuradha Prakash $^{1}$

$7 \quad{ }^{1}$ Food Science Program, Schmid College of Science and Technology, Chapman

8 University, One University Drive, Orange, CA 92866, United States

$9{ }^{2}$ Centro de Investigación en Alimentación y Desarrollo A. C.-Unidad Cuauhtémoc, 10 Av. Río Conchos S/N, Parque Industrial, C.P. 31570, Cd. Cuauhtémoc, Chihuahua,

11 México

$123^{3}$ Universidad de Colima, Bioengineering Laboratory, Km. 9 carretera Coquimatlán-

13 Colima. C.P. 28400. Coquimatlán, Colima, México.

*Corresponding author. E-mail address: jornelas@ciad.mx (J.J. Ornelas-Paz)

17 Running head: Postharvest quality of irradiated oranges

\section{Acknowledgements}

19 This work was supported by a TASC grant from USDA-FAS. J.J. Ornelas-Paz

20 thanks CONACYT (Mexico) for providing support for his sabbatical leave at

21 Chapman University. The authors thank Shantae Thornton and Dhwani Patel for 22 their technical support. 


\section{Abstract}

24 The objective of this study was to determine if oranges in the top and bottom layers

25 within a Standard Place Pack were impacted differently by irradiation after long-term

26 storage. 'Barnfield' Navel oranges were packed in Standard Place Pack cartons and

27 treated with $0,0.15$ or $1 \mathrm{kGy}$ of gamma irradiation. The fruit were stored for three 28 weeks at $5{ }^{\circ} \mathrm{C}$ and then for one week at $20{ }^{\circ} \mathrm{C}$. After storage, the fruit from the top

29 and bottom layers were separately evaluated for quality. The development of stem

30 end rind breakdown (SERB) was the main cause of quality loss and was greater in

31 irradiated fruit in the top layer. Fruit in the bottom layer showed more physical

32 damage (flattening) but lower incidence of SERB. The changes in individual sugar

33 content were minimal but significant for layer. The content of individual organic acids

34 was consistently lower in irradiated fruit from the bottom layer. Layer type showed a 35 stronger effect on phenolic compounds than irradiation dose. The tristimulus color, 36 total soluble solids, titratable acidity, and firmness of fruit were not influenced by 37 irradiation dose or layer type. The results show that damage in irradiated Navel 38 oranges depends on dose and layer, with the top layers showing greater 39 physiological damage and bottom layers showing more physical damage.

42 Keywords: Ionizing energy; Physiological disorders; Chemical composition; Citrus; 43 Phytosanitary treatment; Postharvest quality 
46 The US is one of the largest orange producing countries in the world, with California

47 and Florida providing much of the oranges for the fresh market and for processing,

48 respectively (USDA 2017). Fresh oranges from the US are exported to several

49 countries, mainly to South Korea, Canada, and Japan (AMRC 2013). However, the

50 production of oranges in the US has decreased slightly but continuously in recent

51 years, causing an increase in the importation of oranges from countries such as China,

52 Australia, Mexico, Jamaica, and the Philippines (APHIS 2014; USDA 2017). The high

53 volume of international and domestic trade of oranges can infer a high risk for the

54 spread of quarantine pests. Thus, oranges being imported, exported, or even moved

55 within the US must be subjected to phytosanitary treatments before shipment (APHIS

56 2014). Several postharvest phytosanitary treatments have been approved for citrus

57 fruits but irradiation has advantages over the other treatments in terms of exposure of

58 fruit to unsuitable high or low temperatures for extended periods of time, human

59 safety, and environmental impacts (Hallman 2012).

60 Generic doses of 0.15 and 0.4 kGy are approved to control many classes of insects

61 except the pupae and adult stages of Lepidoptera (APHIS 2014), while a maximum of

$621 \mathrm{kGy}$ is allowed by the FDA for use on fresh fruits and vegetables (Follett and Wall

63 2013; Hallman 2012). The dose of $0.15 \mathrm{kGy}$ is sufficient to control insects commonly

64 found on oranges and may limit the negative effects on quality, which are manifested

65 in oranges as softening, peel injury, chemical (loss of nutrients, bioactive compounds,

66 volatiles) and sensory changes (Ladaniya et al. 2003; McDonald et al. 2013; Miller et

67 al. 2000; Nagai and Moy 1985). Many of these effects have been related to the 
68 irradiation-mediated increase in ethylene biosynthesis and respiration rate (Ladaniya

69 et al. 2003), but the incidence and severity of these negative effects depend on orange

70 variety, maturity stage, and irradiation dose (Bustos and Mendieta 1988; Miller et al.

71 2000; Nagai and Moy 1985).

72 Oranges in the US are generally packed precisely in four layers in $18.1 \mathrm{~kg}$ Standard

73 Place Pack cartons. They are typically packed without protective trays between layers,

74 resulting in the compression of fruit, especially in the bottom layer during long-distance

75 shipping (Moresi et al. 2012). This kind of damage can compromise the appearance

76 of the fruit and might cause the rejection of the entire fruit shipment (Mazidi et al.

77 2016). Compression damage in citrus fruits, as with any other physical damage,

78 triggers a burst of ethylene production (Lu et al. 2014) directly or indirectly impacting

79 the respiration rate, and resulting in softening, peel injury and chemical changes

80 (Porat et al. 2004; Rojas-Argudo et al. 2010, 2012). Compression damage can alter

81 the levels of sugars, organic acids (mainly ascorbic acid), volatiles, and phenols in

82 citrus fruit (Mazidi et al. 2016; Obenland et al., 2018; Rojas-Argudo et al. 2010, 2012).

83 Transportation temperature and distance also influence the severity and incidence of

84 compression damage (Ahmadi 2012; Ahmadi et al. 2010).

85 Irradiation-induced stress in oranges can elicit a similar physiological response to that

86 of compression damage (Mazidi et al. 2016; Rojas-Argudo et al. 2012). Thus, the

87 combination of compression and irradiation might exacerbate postharvest damage in

88 oranges. In our previous work, we noted that the undesirable effects of irradiation on

89 Navel oranges, especially peel injury, seemed to depend on the position of the fruit

90 within the case, but this phenomenon was not systematically investigated (McDonald 
91 et al. 2013), and the literature does not provide any information in this regard. The

92 objective of this study was to determine if oranges in the top and bottom layers within

93 a Standard Place Pack were impacted differently by irradiation after long-term storage.

94 The $0.15 \mathrm{kGy}$ dose was selected since it is the minimum target dose for oriental fruit

95 fly. A dose of $1 \mathrm{kGy}$ was included to accentuate the impacts of irradiation on the fruit

96 to allow these effects to be detected and measured.

$98 \quad$ Materials and Methods

99 Fruit Procurement, Treatment, and Storage

100 'Barnfield' Navel Oranges (Citrus sinensis (L.) Osbeck) (size 72) were harvested from

101 a commercial orchard in Kern County, CA, USA. The fruit were commercially treated

102 and packed by Paramount Citrus Exchange (Delano, CA, USA). The handling involved

103 three washing steps with chlorine; one at dumping point $(150 \mathrm{mg} / \mathrm{L})$, then at high

104 pressure $(200 \mathrm{mg} / \mathrm{L}, 862 \mathrm{kPa}$ ) and a final immersion for $3 \mathrm{~min}$ in $3 \%$ sodium

105 bicarbonate solution containing chlorine $(200 \mathrm{mg} / \mathrm{L})$. After rinsing with water, the fruit

106 were treated with Imazalil $(300 \mathrm{mg} / \mathrm{L})$ for $30 \mathrm{~s}$ in an immersion tank, then rinsed with

107 water. Finally, the fruits were waxed with a carnauba based wax containing Imazalil

$108(1 \mathrm{~g} / \mathrm{L})$ and thiabendazole $(3.5 \mathrm{~g} / \mathrm{L})$. The oranges were bulk packed in $18.14 \mathrm{~kg} \mathrm{(72-}$

10980 fruits) Standard Place Pack cartons $(40.6 \times 27.9 \times 25.4 \mathrm{~cm})$ and refrigerated at 5

$110{ }^{\circ} \mathrm{C}$. In each carton, the fruit were distributed in four layers; each layer containing $\sim 20$

111 fruit. The oranges were transported to Sterigenics, Inc. (Tustin, CA, USA), for

112 treatment, where six cases of oranges were placed two rows high and three across at

113 a precise distance from a ${ }^{60} \mathrm{Co}$ source ( $\left.\sim 37 \mathrm{PBq}\right)$. Dose mapping was conducted by 
114 placing 24 alanine pellet dosimeters (FarWest Technology, Inc., Goleta, CA, USA) at

115 various locations in the cases. The dose rate was determined to be $0.637 \mathrm{~Gy} / \mathrm{s}$. Six

116 cases of oranges were placed exactly in the same configuration as the dummy cases

117 to receive treatment at a target dose of 0.15 and $1 \mathrm{kGy}(4.6-5.5 \%$ uncertainty) and

118 Dmax/Dmin ratio of 1.33 . Midway through treatment, the boxes were rotated $180^{\circ}$ to

119 ensure uniform treatment. After treatment, the oranges were transported to Chapman

120 University, and stored at $5{ }^{\circ} \mathrm{C}$ and $95 \% \mathrm{RH}$ for 3 weeks to simulate sea shipment to

121 Asian markets. After cold storage, the oranges were placed at room temperature (20

$122{ }^{\circ} \mathrm{C}$ ) for one week to simulate retail display. Following this four week storage, twenty

123 fruit from the top and bottom layers of each of the four cases were pooled, to obtain a

124 total of 80 fruit for each layer. Of the 80 fruit per layer, ten were used to measure

125 tristimulus color and ten for firmness. Sixty fruits were distributed in five subsamples,

126 juiced and the juice was used to measure titratable acidity (TA), total soluble solids

127 (TSS), individual sugars, organic acids, and total and individual phenols. Twenty

128 oranges from top and bottom layers from the remaining two cartons were evaluated

129 for stem-end breakdown (SERB), fungal infections, shape deformation and weight

130 loss. All fruits included in the experiment were free of physiological, physical and

131 biological damage (flattening, SERB, fungal infections and insect damage). Their

132 average weight $(270.7 \pm 3.8 \mathrm{~g})$, peel color $\left(L^{\star}=65.1 \pm 0.3, a^{*}=29.4 \pm 0.5, b^{*}=48.1 \pm\right.$

$1330.9)$, internal color $\left(L^{*}=46.4 \pm 0.4, a^{*}=8.7 \pm 0.2, b^{*}=31.1 \pm 0.6\right)$, peel firmness, $(6.8$

$134 \pm 0.5 \mathrm{~N})$, pulp firmness $(3321.8 \pm 173.0 \mathrm{~N} \mathrm{~mm})$, TSS content $(12.6 \pm 0.03 \%)$ and

135 TA $(0.43 \pm 0.006 \%)$ at the beginning of the experiment were characteristic of ripe $136 \quad$ Navel oranges. 


\section{Peel Damage}

138 Shape deformation by compression was reported as the percentage of fruit showing

139 flattening. These fruit were also grouped according to the severity of compression

140 damage. The severity of flattening was estimated by calculating the percent of fruit

141 surface area showing flattening. These areas were converted into a 5 point scale

142 according to Yue et al. (2007), with $0=$ no damage, $1=1-4 \%, 2=5-8 \%, 3=9-12 \%$,

$1434=13-15 \%$, and $5=16 \%$ or more of damaged surface. The fruit surface area was

144 determined by measuring their equatorial diameter and assuming a spherical shape

145 while the flattened areas were measured using a Vernier caliper.

146 The incidence and severity of SERB were determined by digital image analysis, given

147 the irregular shape of SERB lesions and the consequent difficulty to be evaluated

148 using a Vernier caliper. The incidence of SERB was determined by calculating the

149 percent of fruit showing this damage. The severity of SERB was determined by

150 estimating the area and color of SERB lesions by digital image analysis. The peduncle

151 side of 20 fruit per layer was photographed using a digital camera. An algorithm, 152 designed in MATLAB (R2010a, MathWorks, USA), was used to determine the area 153 and tristimulus color of the SERB lesions in the digital images. The digital image is an

$154 M \times N \times P$ array, where $M \times N$ represents the image dimension in pixels, while $P$ is the 155 number of color planes, three in this case, corresponding to the matrices R', G', and $156 \mathrm{~B}^{\prime}$. In order to convert an $\mathrm{R}^{\prime} \mathrm{G}^{\prime} \mathrm{B}^{\prime}$ digital image to an $\mathrm{L}^{*} \mathrm{a}^{*} \mathrm{~b}^{*}$ color space (CIELab), the 157 MatLab object ColorSpaceConverter was used. In the $L^{*} a^{*} b^{*}$ color space, $L^{*}$ indicates 158 lightness, $a^{*}$ is the red $(+a) / g r e e n$ coordinate $(-a)$, and $b^{*}$ is the yellow $(+b) / b l u e$ 159 coordinate (-b) (Chen et al., 2010). For the determination of SERB area, the digital 
160 image was transformed to a gray-scale image. The \% of area showing SERB lesions

161 was calculated relative to the area of the fruit in the picture.

162 The incidence of fungal infections was determined by calculating the percent of fruits

163 per layer showing areas with mycelia. The area of the fungal infection (severity) was

164 not determined since under commercial conditions any fruit showing fungal infection

165 must be discarded, in contrast to fruit showing SERB or flattening.

\section{Tristimulus Color of Fruits}

168 Peel color was measured in areas free of injuries at two equidistant points on the

169 equatorial axis of 10 fruit using a CM-2500d Konica Minolta Spectrophotometer

170 (Ramsey, New Jersey, USA). Then, the oranges were cut at the equatorial axis and

171 two color measurements were taken on the internal surface of each half. The $L^{\star}, a^{\star}$

172 and $b *$ values were recorded.

\section{Firmness}

175 Firmness of the peels and intact segments of the fruit was measured. For peel 176 firmness, four peel sections were vertically excised from 10 fruit using a paring knife 177 and evaluated for penetration resistance to a $3 \mathrm{~mm}$ puncture probe using a TA-XT2 178 Texture Analyzer (Texture Technology Corp; Scarsdale, NY, USA), which moved 179 downward through the peel at $3 \mathrm{~mm} / \mathrm{s}$ until breakpoint. The maximum force $(\mathrm{N})$ 180 required to puncture the peel was recorded. For pulp firmness, the segments from 181 the peeled oranges were carefully separated by hand and distributed in eight 182 subsamples of $150 \mathrm{~g}$ each. Each subsample of intact segments was placed into a 
183 Kramer Shear Cell (TA-91) and the five flat-blade press, set at $80 \mathrm{~mm}$ from the bottom

184 of the cell platform, was moved downward through the segments at $5 \mathrm{~mm} / \mathrm{s}$ for 75

$185 \mathrm{~mm}$. The area (N.mm) under the force deformation curve was determined.

187 Weight Loss, Titratable Acidity (TA) and Total Soluble Solids content (TSS)

188 Weight loss (\%) was determined by measuring the change in weight during storage in

189 the fruit used for peel damage determination. For TA, $5 \mathrm{~g}$ of juice were diluted with 50

$190 \mathrm{~g}$ of water and titrated to a $\mathrm{pH}$ of 8.2 with $0.1 \mathrm{~N} \mathrm{NaOH}$. TA was calculated using the

191 factor of 0.064 for citric acid, according to McDonald et al. (2013). The content of TSS

192 of the juice was directly determined by placing a few drops of juice on the glass surface

193 of a PAL digital refractometer (Atago Co., LTD, Tokyo, Japan).

\section{Sugars}

196 Glucose, fructose, and sucrose were measured according to Ornelas-Paz et al.

197 (2013), with some modifications. An aliquot of juice $(100 \mu \mathrm{L})$ was mixed with $2 \mathrm{~mL}$ of 198 HPLC water. The mixture was filtered with a $45 \mu \mathrm{m}$ pore size acrodisk and 199 automatically injected (20 $\mu \mathrm{L})$ into an Agilent 1100 series HPLC system (Agilent Inc., 200 Santa Clara, CA, USA) equipped with a refractive index detector. The separation was 201 performed in a Sugar SC $1821(8.0 \times 300 \mathrm{~mm}, 6 \mu \mathrm{m})$ column at $80^{\circ} \mathrm{C}$ with a Sugar 202 SC-LG $(6.0 \times 50 \mathrm{~mm}, 10 \mu \mathrm{m})$ precolumn (Showa Denko K.K.; Tokyo, Japan). The 203 mobile phase was $100 \%$ HPLC grade water at a flow rate of $0.8 \mathrm{~mL} / \mathrm{min}$. The sugars 
204 were quantified using calibration curves constructed with at least three independent

205 sets of dilutions of glucose, sucrose, and fructose.

\section{Organic Acids}

207 One $\mathrm{mL}$ of juice was mixed with $3 \mathrm{~mL}$ of $5 \mathrm{mM} \mathrm{H}_{2} \mathrm{SO}_{4}$. The mixture was filtered using 208 a $45 \mu \mathrm{m}$ pore acrodisk and automatically injected $(20 \mu \mathrm{L})$ into the HPLC system 209 described above, which is also equipped with a diode array detector. The separation 210 was performed using an Aminex HPX-87H ion exchange column $(7.8 \times 300 \mathrm{~mm}$; Bio-

211 Rad Laboratories, Hercules, CA, USA) at $60^{\circ} \mathrm{C}$. The mobile phase was $5 \mathrm{mM} \mathrm{H}_{2} \mathrm{SO}_{4}$ 212 and acetonitrile $(90: 10, \mathrm{v} / \mathrm{v})$ at flow rate of $0.4 \mathrm{~mL} / \mathrm{min}$. Oxalic, citric, tartaric, malic,

213 quinnic, succinic, and fumaric acids were monitored at $\lambda=210 \mathrm{~nm}$ while ascorbic acid

214 was monitored at $\lambda=260 \mathrm{~nm}$. The quantification was based on calibration curves

215 constructed with at least three independent sets of dilutions of standard compounds. 216

\section{Phenolic Compounds}

218 The analysis of individual and total phenols was performed simultaneously. The juice

219 was filtered with a membrane of $0.45 \mu \mathrm{m}$ pore size and directly injected $(100 \mu \mathrm{L})$ into 220 the HPLC described previously. The separation of phenolic compounds was 221 performed using a Kinetex C18 column $(4.6 \times 100 \mathrm{~mm})$ (Phenomenex; Torrance, CA,

222 USA) at $30^{\circ} \mathrm{C}$. The phenolic compounds were monitored at $\lambda=280,320,350$ and 520

$223 \mathrm{~nm}$. The mobile phase consisted of $2 \%$ acetic acid (A), and acetonitrile (B), according 224 to the following gradient: $100 \% \mathrm{~A}$ at $0 \mathrm{~min}, 93 \% \mathrm{~A}$ at $12 \mathrm{~min}, 89 \% \mathrm{~A}$ at $20 \mathrm{~min}, 86 \% \mathrm{~A}$ 225 at $35 \mathrm{~min}, 84 \% \mathrm{~A}$ at $36 \mathrm{~min}, 82 \% \mathrm{~A}$ at $41 \mathrm{~min}, 79 \% \mathrm{~A}$ at $44,0 \% \mathrm{~A}$ from $\min 55$ to 
226 60. The flow rate was $1 \mathrm{~mL} / \mathrm{min}$. The phenolic compounds were identified and

227 quantified by using reference compounds. The UV-Vis spectrum of each phenol was

228 also used for identification purposes.

229 For total phenolic content, $100 \mu \mathrm{L}$ of filtered juice were mixed with $100 \mu \mathrm{L}$ of Folin-

230 Ciocalteu reagent, $3 \mathrm{~mL}$ of deionized water and $100 \mu \mathrm{L}$ of $20 \% \mathrm{Na}_{2} \mathrm{CO}_{3}$. The mixture

231 was vigorously shaken for $1 \mathrm{~min}$ and incubated for $1 \mathrm{~h}$ in the dark. The absorbance

232 was evaluated five times at $765 \mathrm{~nm}$ using a FLUOstar Omega microplate reader (BMG

233 LABTECH Inc.; Cary, NC, USA). The absorbance values were corrected with those

234 generated with blank reactions. Quantification was based on a calibration curve

235 constructed with several sets of dilutions of gallic acid. The results were expressed as

236 mg GAE per liter of juice.

237

\section{Statistical Analysis}

239 The effects of irradiation dose and layer were determined using a linear mixed effects

240 model and pairwise Tukey Kramer Test, using a level of significance of 0.05 . Analysis

241 was conducted using R 3.2.3 software with Ime4, multcomp, and car packages ( $R$

242 Core Team, 2015, Vienna, Austria).

243

244 Results and Discussion

245 Peel Damage

246 SERB, flattening and fungal infections were observed in control and irradiated fruit

247 from both layers (Table 1). SERB was characterized by collapsed, darkened, and 
248 sunken rind tissue around the calyx, as described by Ritenour et al. (2004). It was

249 observed after cold storage in all treatments, but was more evident after storage at

250 room temperature. This disorder has been observed in other studies for non-irradiated

251 oranges (Alférez et al., 2003). The incidence of SERB lesions increased with

252 irradiation dose $($ Table 1$)(P<0.05)$. Image analysis showed that the area of the

253 lesions was similar for fruit in the top and bottom layers $(P>0.05)$ (Fig. 1A). Irradiation

254 dose and layer also affected the $L^{*}$ and $b^{*}$ values in the SERB lesions (Figs. 1B and

255 1C). Fruit treated with $1 \mathrm{kGy}$ showed darker lesions as compared to $0.15 \mathrm{kGy}$ and

256 control fruit $(P<0.05)$ and, the fruit from top layer showed darker lesions in all

257 experimental groups as compared with fruit from the bottom layer $(P<0.05)$.

258 Differences in gas composition between the top and bottom layers might explain the

259 differences in SERB incidence. Fruit from the bottom layer might produce more $\mathrm{CO}_{2}$

260 and ethylene because that fruit was subjected to higher stress by compression

261 (flattening). Also, given the higher density of $\mathrm{CO}_{2}$, fruit in the bottom layer was

262 probably exposed to higher $\mathrm{CO}_{2}$ levels which might avoid the oxidation of phenolic

263 compounds. This hypothesis might explain the less darkening (higher $L^{*}$ values) of

264 SERB lesions for control and irradiated fruit in the bottom layer (Fig. 1). Porat et al.

265 (2004) demonstrated that modified atmosphere packaging (reduced levels of $\mathrm{O}_{2}$ and

266 increased levels of $\mathrm{CO}_{2}$ ) reduced SERB in oranges. On the other hand, most of the

$267 \quad \mathrm{C}_{2} \mathrm{H}_{4}$ would diffuse from bottom to the top and accumulate there because of its lower

268 density $\left(\mathrm{CO}_{2}>\mathrm{O}_{2}>\mathrm{C}_{2} \mathrm{H}_{4}\right)$. Higher levels of $\mathrm{C}_{2} \mathrm{H}_{4}$ could lead to increased phenylalanine

269 ammonia lyase (PAL) activity resulting in the production of phenols which are then

270 oxidized by polyphenol oxidase and peroxidase to o-quinones that further polymerize 
271 to the brown pigments characteristic of SERB lesions (Banerjee et al., 2015).

272 Unfortunately, the low irradiation doses do not inactivate the polyphenol oxidase and

273 peroxidase responsible for phenol oxidation and formation of brown pigments. Alférez

274 et al. (2003) associated the ethylene production of oranges with their susceptibility to

275 develop postharvest browning. Increased ethylene production has also been

276 associated with the development of peel injury in irradiated and wounded citrus fruits,

277 probably due to its involvement in the activation of enzymes such as peroxidase and

278 PAL which are resposible for citrus browning (Ladaniya 2008; Lu et al. 2014;

279 McDonald et al. 2000; Porat et al. 2004). PAL was observed to increase immediately

280 after irradiation treatment in Clementine mandarins (Oufedjikh et al., 2000) and

281 grapefruit (Riov et al., 1975) and correlated with an increase in phenolic compounds

282 in damaged peel cells. Guerrero et al. (1967) attributed rapid rind breakdown to higher

283 respiratory rates in 'Washington Navel' oranges irradiated with 0.5 to $6 \mathrm{kGy}$.

284 Flattening was clearly observed in all tested fruit. As expected, fruit in the bottom layer

285 always presented larger flat areas than fruit in top layer for all treatments $(P<0.05)$

286 (Table 2). However, although the incidence of flattening in both layers decreased as

287 the irradiation dose increased, the severity of flattening increased with irradiation dose

288 (Tables 1 and 2). Thus, fruit treated with 0.15 and $1 \mathrm{kGy}$ showed a lower incidence of

289 flattening as compared to control fruit, but the severity of the damage increased with

290 irradiation dose (Tables 1 and 2). Nevertheless, the overall flattened area was no

291 more than $12 \%$ of total surface in irradiated fruit and was not the primary contributing

292 factor to a decrease in quality. These findings demonstrate a differential effect of

293 irradiation in non-damaged and compressed (damaged) areas of the oranges. Some 
294 studies have demonstrated that irradiation causes different biochemical responses in

295 wounded citrus fruits as compared to fruit that are not wounded (Rojas-Argudo et al,

296 2012); however, there is no information regarding biochemical responses of oranges

297 subjected to compression stress and irradiation as compared with oranges subjected

298 to only irradiation. Besides the mechanical weakening of fruit by compression,

299 ethylene biosynthesis in compressed areas of irradiated oranges might be higher than

300 in not compressed areas, causing a higher enzymatic softening around flattened areas

301 and increasing the severity of this kind of damage. The individual effects of

302 compression and irradiation on ethylene biosynthesis in citrus fruit have been

303 demonstrated previously (Ladaniya et al. 2003; Lu et al. 2014).

304 The incidence of fungal infections was similar for fruit in both layers for all experimental

305 groups $(P>0.05)$ (Table 1). Vilanova et al. (2014) observed that the susceptibility of

306 oranges to postharvest infections was increased by fruit wounding. In our study, the

$3070.15 \mathrm{kGy}$ dose did not increase mold growth as compared to the control. However,

308 fruit treated with a dose of 1 kGy showed higher levels of fungal infection most likely

309 due to damage caused to fruit cell walls and release of nutrients that encourage fungal

310 growth (Ladaniya et al. 2003; Zhang et al. 2014). While flattening and decay incidence

311 are both higher in bottom layer fruit and fruit treated at $1 \mathrm{kGy}$, the high occurrence of

312 decay in the top layer of the $1 \mathrm{kGy}$ fruit, suggests that irradiation by itself at this dose

313 level enhances decay. Rojas-Argudo et al. (2012) demonstrated that low irradiation

314 doses (0.51 kGy) stimulated the biosynthesis of antifungal compounds in citrus fruits

315 and that higher irradiation doses (0.875 kGy) inhibited such biosynthesis, favoring 316 postharvest infections. 


\section{Tristimulus Color, Firmness and Weight Loss}

319 Neither irradiation dose nor fruit layer affected tristimulus color and firmness of peel

320 or pulp ( $\mathrm{P}>0.05)$ (data not shown). Similarly, McDonald et al. (2013) demonstrated

321 that the color of Navel oranges was not affected by irradiation doses of up to $0.6 \mathrm{kGy}$.

322 Weight loss after storage ranged from 6.4 to $9 \%$ and was not impacted by irradiation

323 treatment and layer type ( $P>0.05)$ (data not shown). Miller et al. (2000) demonstrated

324 that irradiation at $0.15,0.3$ and $0.45 \mathrm{kGy}$ did not significantly alter the color, firmness

325 and weight loss in five orange cultivars, including Navel oranges.

326

327 Total Soluble Solids (TSS) and Sugars

328 TSS values, ranging from 12 to $12.7 \%$ (data not shown), were similar to those reported

329 previously for oranges (McDonald et al. 2013; Miller et al. 2000), and were not affected

330 by irradiation dose or layer type ( $>0.05)$. Similarly, Miller et al. (2000) evaluated the

331 effect of irradiation (0.15-0.45 kGy) on TSS content in fruit from five orange cultivars,

332 including Navel oranges, and found that irradiation did not affect TSS.

333 Sucrose was the most abundant of measured sugars in the oranges $(P<0.05)$,

334 followed by glucose and fructose, which showed similar content ( $P>0.05)$ (Fig. 2).

335 Similar sugar composition has been reported previously for oranges (Kelebek et al.

336 2009; Roussos 2011). The changes in sugar content as a function of irradiation dose

337 and layer type were very small but significant in some cases. In fruit from top layer,

338 sucrose content tended to decrease with the irradiation dose while glucose and

339 fructose increased $(P<0.05)$. Similar results were reported for mandarins treated with 
$340 \quad 0.15,0.4$ and $1 \mathrm{kGy}$ (Ornelas-Paz et al. 2017). However, irradiation caused a different

341 alteration of sugar content in fruit in the bottom layer, where a slight decreasing trend

342 was observed for glucose and fructose while sucrose content was not altered

343 significantly $(P>0.05)$ (Fig. 2). These opposite trends in sugars for fruit in top and

344 bottom layers suggest sugar conversion in the top layer fruit and increased usage of

345 glucose and fructose in the bottom layer fruit. Some studies have demonstrated that

346 irradiation can increase the activity or biosynthesis of enzymes involved in sugar

347 conversion (invertases, sucrose synthases, fructokinase, hexokinase and sucrose

348 phosphate synthases) (Shi et al. 2016; Yativ et al. 2010). Other studies have

349 demonstrated that, depending on severity, physical damage can induce biological

350 stress in fruits and ethylene biosynthesis, causing the expression of gene coding

351 enzymes involved in the sugar composition of citrus fruits (Ladaniya et al. 2003; Lu et

352 al. 2014; Rojas-Argudo et al. 2012; Shi et al. 2016). The conversion of sucrose to

353 glucose and fructose is a genetic response of fruit to satisfy the demand for hexoses

354 due to the increased respiration rate mediated by ethylene exposure and/or wounding,

355 but generated hexoses are also used for signaling and as precursors for sucrose

356 biosynthesis in highly damaged fruit because sucrose confers tolerance to fruit against

357 damage (Cao et al., 2013; Lin et al., 2015). Thus, bottom fruit showed lower levels of

358 glucose and fructose without alteration of the sucrose content probably because the

359 hexoses were used for respiration and also to maintain normal levels of the protective 360 sucrose.

361

362 Titratable Acidity (TA) and Organic Acids 
363 TA values (0.44-0.49\%) showed no effect of layer or irradiation dose $(P>0.05)$ (data

364 not shown). Other studies have also shown that irradiation doses of up to $3 \mathrm{kGy}$ do

365 not significantly alter the TA of orange juice (Miller et al. 2000). Our TA values were 366 similar to those previously reported for oranges (Flores et al. 2012; Kelebek et al.

367 2009; Roussos et al. 2011). The most abundant organic acids found in 'Barnfield'

368 Navel oranges were citric and quinnic acids while fumaric and oxalic were the least 369 abundant, as reported by Flores et al. (2012).

370 With few exceptions, the content of tested individual organic acids was consistently

371 lower in irradiated fruit in the bottom layer as compared with that of top layer $(P<0.05)$

372 (Fig. 3), suggesting that the metabolic activity was exacerbated in irradiated fruit by

373 irradiation and physical damage, leading to a higher respiration rate and consequently

374 to an increased utilization of organic acids. Different types of stress accelerate the

375 glycolysis and tricarboxylic acid cycle in citrus fruits, enhancing the transition from

376 sucrose metabolism to organic acid metabolism and leading to extensive citrate

377 degradation mainly through the gamma-aminobutyric acid and acetyl-CoA pathways

378 (Lin et al., 2015). These changes are genetically regulated, with the gene cascade

379 Aco3-IDH2/3-GAD4 serving as the major contributor to acid degradation (Chen et al.,

380 2012). Thus, irradiation and physical damage might induce a higher reduction of the

381 organic acid content in the bottom fruit as compared with the top fruit. This behavior

382 was clearly observed for ascorbic acid, which has been related to oxidation of ascorbic

383 acid by irradiation-generated reactive oxygen species (Wong and Kitts 2001).

384 Recently, Ramírez-Cahero and Valdivia-López (2018) demonstrated that irradiation

$385(0.5,0.7$ and $1 \mathrm{kGy})$ of ascorbic acid model solutions led to the formation of several 
compounds (2-furaldehyde, 2(5H)-furanone, 2-furoic acid, furfuryl alcohol, 387 glycolaldehyde, and formic, oxalic, succinic and L-tartaric acids) with the formation of 388 these compounds dependent on irradiation dose. This direct degradation of certain 389 organic acids by irradiation, and consequent increase in others could occur in our 390 study, but the bottom layer almost always showed a reduction in organic acids at 1 391 kGy, due most likely to accelerated glycolysis and respiration rate of the bottom layer 392 fruit. The negative effects of irradiation and mechanical damage on ascorbic acid 393 content have been separately reported for oranges (Ladaniya 2008; Lee and Kader 394 2000). In contrast to irradiated fruit, the acid content in control group was generally 395 higher in fruit from bottom layer as compared with that of the top layer $(P<0.05)$. 396 Recently, Ornelas-Paz et al. (2017) also observed a generally higher content of 397 organic acids in non-irradiated mandarins after simulated sea shipment as compared 398 to irradiated fruit. Our findings demonstrated that irradiation and compression and their 399 combination affected differentially the metabolism of oranges.

\section{Total and Individual Phenols}

402 The total phenolic content in fruit of the same layer was unchanged with irradiation 403 ( $P>0.05)$, but showed minor differences between layers. Fruit in the bottom layer 404 exhibited a lower total phenolic content, as compared to fruit in the top layer $(P<0.05)$ 405 (Fig. 4). This suggested a wounding-mediated deterioration of phenolic compounds. 406 The concentration of phenolic substances following irradiation can increase with low 407 doses but higher doses can lead to reduced synthesis or destruction (Oufedjikh et al., 408 2000). Some studies have demonstrated that the combination of wounding and 
409 irradiation at some doses reduced the biosynthesis of phenolic compounds, as

410 compared with the individual effects of wounding and irradiation, promoting a higher

411 incidence of fungal infections (Rojas-Argudo et al., 2012). This might explain the

412 higher incidence of fungal infections observed in this study for fruit in the bottom layer

413 (Table 1). Some studies have demonstrated that wounding causes an immediate

414 increase in the concentration of antifungal compounds, i.e. phytoalexins, which

415 prevent spore germination and mycelium growth but do not damage the fungal

416 structures or their viability (Kim et al., 1991; Ben Yehoshua et al., 1992). This

417 wounding-mediated increase of antifungal compounds is transient (Rojas-Argudo et

418 al., 2012), favoring the initiation of the disease in wounds as the levels of antifungal

419 compounds decrease during storage (Kim et al., 1991; Ben Yehoshua et al., 1992).

420 Thus, the combination of this transient effect of wounding and the well-known

421 phytotoxic effect of irradiation can, in combination, exacerbate the incidence of fungal

422 infections.

423 Some phenolic acids (chlorogenic, $p$-coumaric, and ferulic acids) and flavonoids (rutin,

424 narirutin, hesperidin and naringenin) were identified and quantified in the juice of the

425 tested fruit (Fig. 4). The content of narirutin (93.3-100.2 mg/L) did not change

426 significantly as a function of irradiation or layer type $(P>0.05)$ (data not shown).

427 Hesperidin, narirutin, and naringenin were the most abundant phenolic compounds in

428 tested oranges. Similar concentrations of these compounds have been reported

429 previously for oranges (Agcam et al. 2014; Rocco et al. 2014). In general, oranges in

430 the bottom layer had a lower $(P<0.05)$ concentration of hesperidin, $p$-coumaric acid,

431 rutin and naringenin compared to oranges in the top layer, although this trend was 
432 less evident for naringenin. Wounding and other types of mechanical injury increase

433 PAL activity and the content of phenolic compounds. However, irradiation is able to

434 inhibit the wounding-mediated activation of PAL, favoring the reduction of phenolic

435 content by injury (Banerjee et al., 2015). This might be the reason why fruit from

436 bottom layer showed a lower content of individual phenols. In contrast, the content of

437 chlorogenic acid was lower in bottom layer of control fruit, while the opposite was

438 observed for irradiated oranges $(P<0.05)$. This phenomenon might be a consequence

439 of irradiation-mediated transformation of phenols. As indicated above, the content of

440 total phenols showed minor changes among experimental groups, suggesting the

441 transformation of phenolic compounds by irradiation or compression damage, as

442 reported by Breitfellner et al. (2003) in irradiated strawberries. In our study, the effect

443 of irradiation dose on individual phenolic compounds was lower than that of the layer

444 type $(P<0.05)$. Only the content of hesperidin and chlorogenic acid was clearly 445 affected by irradiation dose $(P<0.05)$. McDonald et al. (2013) did not observe changes

446 in the phenolic content of Navel oranges treated with several irradiation doses (0.2-

$4470.6 \mathrm{kGy}$ ). In our study, the phenolic content in tested fruit depended on layer type,

448 showing the negative effect of compression damage on this quality attribute. Several

449 studies have already demonstrated that physical damage of citrus fruits alters the

450 content of some individual phenols (Mazidi et al. 2016; Rojas-Argudo et al. 2010,

451 2012). Our study demonstrated that the combination of physical damage and 452 irradiation affected differently the content of phenolic compounds of citrus fruits. 


\section{Conclusions}

455 This work demonstrated that the position of the fruit within a case plays a role in the

456 postharvest quality of irradiated oranges. The observed chemical changes seemed to

457 be a response to stress caused by irradiation as well as location in the case, as

458 evidenced by small alterations in sugars, acids and phenol compounds. Irradiation

459 exacerbated SERB but unexpectedly this disorder was more severe in the top than in

460 the bottom fruit, probably due to differences in the gas composition and/or relative

461 humidity inside the case or phenolic compounds. Flattening and fungal decay

462 depended on irradiation dose and layer type, once again highlighting the combined

463 effect of irradiation and fruit placement in the case. This study shows that for large

464 and heavy fruit such as oranges, which are often packed in multiple layers, packaging

465 type should be considered when evaluating the effect of irradiation on quality. Fruit

466 treated at $0.15 \mathrm{kGy}$ showed minimal alterations in quality independent of fruit position

467 inside the case, demonstrating that Navel oranges tolerate phytosanitary irradiation at 468 this low dose.

\section{$470 \quad$ References}

471 Agcam, E., Akyıldı, A., \& Akdemir Evrendilek, G. (2014). Comparison of phenolic 472 compounds of orange juice processed by pulsed electric fields (PEF) and 473 conventional thermal pasteurisation. Food Chemistry, 143, 354-361, 474 doi:https://doi.org/10.1016/j.foodchem.2013.07.115.

475 Ahmadi, E. (2012). Bruise susceptibilities of kiwifruit affected by impact and fruit $476 \quad$ properties. Research in Agricultural Engineering, 52(3), 107-113. 
Ahmadi, E., Ghassemzadeh, H., Sadeghi, M., M., M., \& Neshat, S. (2010). The effect of impact and fruit properties on the bruising of peach. Journal of Food Engineering, 97, 110-117, https://doi.org/10.1016/j.jfoodeng.2009.09.024

Alférez, F., Agusti, M., \& Zacarías, L. (2003). Postharvest rind staining in Navel oranges is aggravated by changes in storage relative humidity: effect on respiration, ethylene production and water potential. Postharvest Biology and Technology, 28(1), 143-152, https://doi.org/10.1016/S0925-5214(02)00120-5

AMRC (2013). [AMRC] Agricultural Marketing Resource Center. Citrus Profile. http://www.agmrc.org/commodities__products/fruits/citrus/citrus-profile/. Accessed 6 March 2015.

APHIS (2014). [APHIS] Animal and Plant Health Inspection Service. Proposes to allow the importation of fresh citrus from China into the continental United States.http://www.aphis.usda.gov/newsroom/2014/08/pdf/china_citrus_import ation.pdf. Accessed 2 February2015.

Banerjee, A., Penna, P., Variyar, P.S., \& Sharma, A. (2015). Gamma irradiation inhibits wound induced browning in shredded cabbage. Food Chemistry, 173, 38-44, https://doi.org/10.1016/j.foodchem.2014.09.166

Ben Yehoshua, S., Rodov, V., Kim, J.J., \& Carmeli, S. (1992). Performed and induced antifungal materials of citrus-fruits in relation to the enhancement of decay resistance by heat and ultraviolet treatments. Journal of Agricultural and Food Chemistry, 40, 1217-1221, DOI: 10.1021/jf00019a029 
498 Breitfellner, F., Solar, S., \& Sontag, G. (2003). Radiation induced chemical changes of phenolic compounds in strawberries. Radiation Physics and Chemistry, 67(3), 497-499, https://doi.org/10.1016/S0969-806X(03)00092-6

501 Bustos, M. E., \& Mendieta, R. C. (1988). Physiological evaluation of Valencia oranges treated with cobalt 60 gamma radiation. International Journal of Radiation Applications and Instrumentation. Part C. Radiation Physics and Chemistry, 31(1-3), 215-223, https://doi.org/10.1016/1359-0197(88)90129-4

Cao, S., Yang, Z., \& Zheng, Y. (2013). Sugar metabolism in relation to chilling tolerance of loquat fruit. Food Chemistry, 136, 139-143,

508 Chen, M., Jiang, Q., Yin, X. R., Lin, Q., Chen, J. Y., Allan, A. C., Xu, C. J., \& Chen, 509 https://doi.org/10.1016/j.foodchem.2012.07.113

512 Chen, Z., Zhu, C., Zhang, Y., Niu, D., \& Du, J. (2010). Effects of aqueous chlorine 513 dioxide treatment on enzymatic browning and shelf-life of fresh-cut asparagus

516 Flores, P., Hellín, P., \& Fenoll, J. (2012). Determination of organic acids in fruits and 517 vegetables by liquid chromatography with tandem-mass spectrometry. Food 518 Chemistry, 132(2), 1049-1054, doi:https://doi.org/10.1016/j.foodchem.2011.10.064. 
520 Follett, P. A., \& Wall, M. M. (2013). Phytosanitary irradiation for export of fresh 521 produce: commercial adoption in Hawaii and current issues. Journal of 522 Radioanalytical and Nuclear Chemistry, 296(1), 517-522, doi:10.1007/s10967$523 \quad$ 012-1970-0.

524 Guerrero, F., Maxie, E., Johnson, C., Eaks, I., \& Sommer, N. (1967) Effects of 525 postharvest gamma irradiation on orange fruits. In Proceedings of the American $526 \quad$ Society for Horticultural Science. 90, 515-540

527 Hallman, G. J. (2012). Generic phytosanitary irradiation treatments. Radiation Physics

528 and Chemistry, 81(7), 861-866, 529 doi:https://doi.org/10.1016/j.radphyschem.2012.03.010.

530 Kelebek, H., Selli, S., Canbas, A., \& Cabaroglu, T. (2009). HPLC determination of 531 organic acids, sugars, phenolic compositions and antioxidant capacity of 532 orange juice and orange wine made from a Turkish cv. Kozan. Microchemical 533 Journal, 91(2), 187-192, doi:https://doi.org/10.1016/j.microc.2008.10.008.

534 Kim, J.J., Ben-Yehoshua, S., Shapiro, B., Henis, Y., \& Carmeli, S. (1991). 535 Accumulation of scoparone in heat-treated lemon fruit inoculated with 536 Penicillium digitatum Sacc. Plant Physiology, 97, 880-885, DOI: $537 \quad$ https://doi.org/10.1104/pp.97.3.880

538 Ladaniya, M. S. (2008). Citrus Fruit: Biology, Technology, and Evaluation (Citrus $539 \quad$ Fruit). San Diego: Academic Press.

540 Ladaniya, M. S., Singh, S., \& Wadhawan, A. K. (2003). Response of 'Nagpur' 541 mandarin, 'Mosambi' sweet orange and 'Kagzi' acid lime to gamma radiation. 

doi:https://doi.org/10.1016/S0969-806X(02)00480-2.

544 Lee, S. K., \& Kader, A. A. (2000). Preharvest and postharvest factors influencing 545 vitamin C content of horticultural crops. Postharvest Biology and Technology, 20(3), 207-220, doi:https://doi.org/10.1016/S0925-5214(00)00133-2.

547 Lin, Q., Wang, C., Dong, W., Jiang, Q., Wang, D., Li, S., Chen, M., Liu, C., Sun, C., \& 548 Chen, K. (2015). Transcriptome and metabolome analyses of sugar and organic acid metabolism in Ponkan (Citrus reticulata) fruit during fruit maturation. Gene, 554, 64-74, https://doi.org/10.1016/j.gene.2014.10.025

Liu, C., Cai, L., Han, X., \& Ying, T. (2011). Temporary effect of postharvest UV-C irradiation on gene expression profile in tomato fruit. Gene, 486(1), 56-64,

Lu, L., Xu, S., Zeng, L., Zheng, X., \& Yu, T. (2014). Rhodosporidium paludigenum 555 induced resistance in Ponkan mandarin against Penicillium digitatum requires ethylene-dependent signaling pathway. Postharvest Biology and Technology,

Mazidi, M., Sadrnia, H., \& Khojastehpour, M. (2016). Evaluation of orange mechanical damage during packaging by study of changes in firmness. International Food Research Journal, 23(2), 899-903.

561 McDonald, H., Arpaia, M. L., Caporaso, F., Obenland, D., Were, L., Rakovski, C., et 562 al. (2013). Effect of gamma irradiation treatment at phytosanitary dose levels 563 on the quality of 'Lane Late' Navel oranges. Postharvest Biology and 564 Technology, 86, 91-99, doi:10.1016/j.postharvbio.2013.06.018. 
565 McDonald, R., Miller, W., \& McCollum, T. (2000). Canopy position and heat treatments influence gamma-irradiation-induced changes in phenylpropanoid metabolism in grapefruit. Journal of the American Society for Horticultural Science, 125(3), 364-369.

Miller, W. R., McDonald, R. E., \& Chaparro, J. (2000). Tolerance of selected orange and mandarin hybrid fruit to low-dose irradiation for quarantine purposes. HortScience, 35(7), 1288-1291.

572 Moresi, M., Pallottino, F., Costa, C., \& Menesatti, P. (2012). Viscoelastic properties of 573 tarocco orange fruit. Food and Bioprocess Technology, 5(6), 2360-2369, doi:10.1007/s11947-011-0528-4.

575 Nagai, N. Y., \& Moy, J. H. (1985). Quality of gamma irradiated California Valencia 576

578 Obenland, D., Collin, S., Sievert, J., Fjeld, K., Doctor, J., \& Arpaia, M. L. (2008). oranges. Journal of Food Science, 50(1), 215-219, doi:10.1111/j.1365-

\section{2}

583 Commercial packing and storage of Navel oranges alters aroma volatiles and reduces flavor quality. Postharvest Biology and Technology, 47(2), 159-167, 2621.1985.tb13312.x.

Ornelas-Paz, J. d. J., Yahia, E. M., Ramirez-Bustamante, N., Perez-Martinez, J. D., 
attributes and chemical composition of organic strawberry fruit (Fragaria $x$ ananassa Duch, Cv. Albion) at six stages of ripening. Food Chemistry, 138(1), 372-381, doi:10.1016/j.foodchem.2012.11.006.

591 Oufedjikh, H., Mahrouz M., Amiot, M.J., \& Lacroix, M. (2000). Effect of $\gamma$-irradiation on phenolic compounds and phenylalanine ammonia-lyase activity during storage in relation to peel injury from peel of Citrus clementina Hort. Ex. Tanaka. Journal of Agriculture and Food Chemistry, 48, 559-565, DOI: 10.1021/jf9902402

Porat, R., Weiss, B., Cohen, L., Daus, A., \& Aharoni, N. (2004). Reduction of postharvest rind disorders in citrus fruit by modified atmosphere packaging. Postharvest Biology and Technology, 33(1), 35-43, doi:https://doi.org/10.1016/j.postharvbio.2004.01.010.

Ramírez-Cahero, H.F., \& Valdivia-López, M.A. ( 2018). Effect of gamma radiation on sugars and vitamin C: Radiolytic pathways. Food Chemistry, 245, 1131-1140, https://doi.org/10.1016/j.foodchem.2017.11.057

Riov, J. (1975). Histochemical evidence for the relationship between peel damage and the accumulation of phenolic compounds in gamma-irradiated citrus fruit. Radiation Botany. 15, 257-260, https://doi.org/10.1016/S0033-7560(75)80024(2004). Effect of rootstock on stem-end rind breakdown and decay of fresh citrus. HortTechnology, 14(3), 315-319. 
610 Rocco, A., Fanali, C., Dugo, L., \& Mondello, L. (2014). A nano-LC/UV method for the analysis of principal phenolic compounds in commercial citrus juices and evaluation of antioxidant potential. Electrophoresis, 35(11), 1701-1708, doi: 10.1002/elps.201300621

614 Rojas-Argudo, C., Ángel Del Río, M., Montesinos-Herrero, C., \& Palou, L. (2010).

615 Effects of $\mathrm{CO}_{2}$ and $\mathrm{O}_{2}$ shocks at high temperature on postharvest quality of cold-stored citrus fruit. International Journal of Food Science \& Technology,

618 Rojas-Argudo, C., Palou, L., Bermejo, A., Cano, A., del Río, M. A., \& González-Mas, M. C. (2012). Effect of X-ray irradiation on nutritional and antifungal bioactive 45(10), 2062-2070, doi:10.1111/j.1365-2621.2010.02371.x. compounds of 'Clemenules' clementine mandarins. Postharvest Biology and Technology, 68, 47-53, doi:https://doi.org/10.1016/j.postharvbio.2012.02.004.

Roussos, P. A. (2011). Phytochemicals and antioxidant capacity of orange (Citrus sinensis (I.) Osbeck cv. Salustiana) juice produced under organic and integrated farming system in Greece. Scientia Horticulturae, 129(2), 253-258, doi:https://doi.org/10.1016/j.scienta.2011.03.040.

Saltveit, M. E. (2000). Wound induced changes in phenolic metabolism and tissue browning are altered by heat shock. Postharvest Biology and Technology, 21(1), 61-69, doi:https://doi.org/10.1016/S0925-5214(00)00165-4. fruit treated with blue light after harvest exhibit enhanced sugar production and expression of cryptochrome genes. Postharvest Biology and Technology, 111, 197-204, doi:https://doi.org/10.1016/j.postharvbio.2015.08.013. 
633 USDA, 2017. Citrus: world markets and trade. Foreign Agricultural Service/USDA $634 \quad$ Office of Global Analysis. July, 2017.

635 Vilanova, L., Torres, R., Usall, J., Teixidó, N., González-Candelas, L., Viñas, I., et al. 636 (2014). Effect of fruit maturity stage of orange on the wound response to 637 Penicillium digitatum (pathogen) and P. expansum (non-host pathogen). In II 638 International Symposium on Discovery and Development of Innovative 639 Strategies for Postharvest Disease Management 1053 (pp. 177-183).

640 Wong, P. Y. Y., \& Kitts, D. D. (2001). Factors influencing ultraviolet and electron beam 641 irradiation-induced free radical damage of ascorbic acid. Food Chemistry, 74, 642 75-84, https://doi.org/10.1016/S0308-8146(01)00101-7

643 Yativ, M., Harary, I., \& Wolf, S. (2010). Sucrose accumulation in watermelon fruits: 644 Genetic variation and biochemical analysis. Journal of Plant Physiology, 645 167(8), 589-596, doi:https://doi.org/10.1016/j.jplph.2009.11.009.

646 Yue, C., Jensen, H. H., Mueller, D. S., Nonnecke, G. R., Bonnet, D., \& Gleason, M. L. 647 (2007). Estimating consumers' valuation of organic and cosmetically damaged $648 \quad$ apples. HortScience, 42(6), 1366-1371.

649 Zhang, K., Deng, Y., Fu, H., \& Weng, Q. (2014). Effects of Co-60 gamma-irradiation 650 and refrigerated storage on the quality of Shatang mandarin. Food Science and $651 \quad$ Human Wellness, 3, 9-15, https://doi.org/10.1016/j.fshw.2014.01.002

\section{Table captions}


654 Table 1. Incidence of stem end rind breakdown (SERB), flattening and fungal

655 infections in oranges taken from top and bottom layers of Standard Place Pack cartons

656 after storage $\left(3\right.$ weeks at $5^{\circ} \mathrm{C}+1$ week at $\left.20^{\circ} \mathrm{C}\right)$.

657 Table 2. Percentage of fruits from top and bottom layers of Standard Place Pack

658 cartons showing different levels of flattening after storage ( 3 weeks at $5{ }^{\circ} \mathrm{C}+1$ week

659 at $\left.20^{\circ} \mathrm{C}\right)$.

660 Figure captions

661 Figure 1. Percentage of fruit surface area affected by SERB $(A)$ and $L^{*}(B)$ and $b^{*}(C)$ 662 values on SERB lesions in oranges taken from top ( $(-)$ and bottom ( 663 of Standard Place Pack cartons after storage ( 3 weeks at $5{ }^{\circ} \mathrm{C}+1$ week at $20^{\circ} \mathrm{C}$ ). 664 Data represent the mean value of twenty fruits \pm the standard error.

665 Figure 2. Content of sucrose, glucose, and fructose in juice of Navel oranges taken 666 from top ( $)$ and bottom (ㅁ) layers of Standard Place Pack cartons after 667 storage ( 3 weeks at $5{ }^{\circ} \mathrm{C}+1$ week at $20^{\circ} \mathrm{C}$ ). Data represent the mean value of five 668 measurements \pm the standard error.

669 Figure 3. Content of organic acids in juice of Navel oranges taken from top (ב) 670 and bottom (프) layers of Standard Place Pack cartons after storage (3 weeks at 5 $671{ }^{\circ} \mathrm{C}+1$ week at $20^{\circ} \mathrm{C}$ ). Data represent the mean value of five measurements \pm the 672 standard error.

673 Figure 4. Content of total and individual phenols in juice of Navel oranges taken from

674 top (ב) and bottom ( $(-)$ layers of Standard Place Pack cartons after storage (3 675 weeks at $5{ }^{\circ} \mathrm{C}+1$ week at $20^{\circ} \mathrm{C}$ ). Data represent the mean value of five 676 measurements \pm the standard error. 
Table 1.

\begin{tabular}{|l|l|c|c|c|}
\hline \multirow{2}{*}{ Irradiation dose (kGy) } & \multirow{2}{*}{ Layer } & \multicolumn{3}{|c|}{ Damaged fruit (\%) } \\
\cline { 3 - 5 } & Top & $10.0 \pm 10.0 \mathrm{a}$ & $58.8 \pm 21.2 \mathrm{~b}$ & \multicolumn{2}{|c|}{ Fungal infections } \\
\hline 0 & Bottom & $6.3 \pm 6.3 \mathrm{a}$ & $100 \pm 0 \mathrm{a}$ & $19.4 \pm 2.3 \mathrm{a}$ \\
\hline 0.15 & Top & $48.2 \pm 23.2 \mathrm{a}$ & $35.7 \pm 35.7 \mathrm{~b}$ & $12.1 \pm 0.4 \mathrm{a}$ \\
\hline & Bottom & $16.3 \pm 3.8 \mathrm{~b}$ & $95 \pm 5.0 \mathrm{a}$ & $13.9 \pm 2.8 \mathrm{a}$ \\
\hline 1 & Top & $100 \pm 0 \mathrm{a}$ & $6.3 \pm 6.3 \mathrm{~b}$ & $22.2 \pm 0.7 \mathrm{a}$ \\
\hline & Bottom & $100 \pm 0 \mathrm{a}$ & $81.3 \pm 6.3 \mathrm{a}$ & $27.8 \pm 5.6 \mathrm{a}$ \\
\hline
\end{tabular}

Data represent the mean values \pm the standard error. Mean values in the same column for every irradiation dose connected by the same letter are not significantly different. 
Table 2

\begin{tabular}{|c|c|c|c|c|c|c|c|}
\hline \multirow{2}{*}{$\begin{array}{l}\text { Irradiation dose } \\
\text { (kGy) }\end{array}$} & \multirow[b]{2}{*}{ Layer } & \multicolumn{6}{|c|}{ Damage level } \\
\hline & & 0 & 1 & 2 & 3 & 4 & 5 \\
\hline \multirow[t]{2}{*}{0} & Top & $41.3 \pm 21.3 a$ & $58.8 \pm 21.3 a$ & $0.0 \pm 0.0 b$ & $0.0 \pm 0.0 a$ & $0.0 \pm 0.0 a$ & $0.0 \pm 0.0 a$ \\
\hline & Bottom & $0.0 \pm 0.0 b$ & $87.5 \pm 12.5 a$ & $12.5 \pm 0.0 \mathrm{a}$ & $0.0 \pm 0.0 a$ & $0.0 \pm 0.0 a$ & $0.0 \pm 0.0 a$ \\
\hline \multirow[t]{2}{*}{0.15} & Top & $64.3 \pm 35.7 a$ & $35.7 \pm 35.7 a$ & $0.0 \pm 0.0 b$ & $0.0 \pm 0.0 b$ & $0.0 \pm 0.0 a$ & $0.0 \pm 0.0 a$ \\
\hline & Bottom & $5.0 \pm 5.0 b$ & $55.0 \pm 5.0 \mathrm{a}$ & $22.5 \pm 2.5 a$ & $17.5 \pm 7.5 \mathrm{a}$ & $0.0 \pm 0.0 a$ & $0.0 \pm 0.0 a$ \\
\hline \multirow[t]{2}{*}{1} & Top & $93.8 \pm 6.3 a$ & $6.3 \pm 6.3 b$ & $0.0 \pm 0.0 b$ & $0.0 \pm 0.0 b$ & $0.0 \pm 0.0 a$ & $0.0 \pm 0.0 a$ \\
\hline & Bottom & $18.8 \pm 6.3 b$ & $50.0 \pm 0 a$ & $18.8 \pm 6.3 a$ & $12.5 \pm 0.0 \mathrm{a}$ & $0.0 \pm 0.0 a$ & $0.0 \pm 0.0 a$ \\
\hline
\end{tabular}

Severity values were based on \% of fruit surface showing flat areas: 0 (no damage), 1 (1-4\%), 2 (5-8\%), 3 (9-12\%), 4 (13$15 \%)$, and $5(>16 \%)$. Data represent the mean values \pm the standard error. Mean values in the same column for every irradiation dose connected by the same letter are not significantly different. 

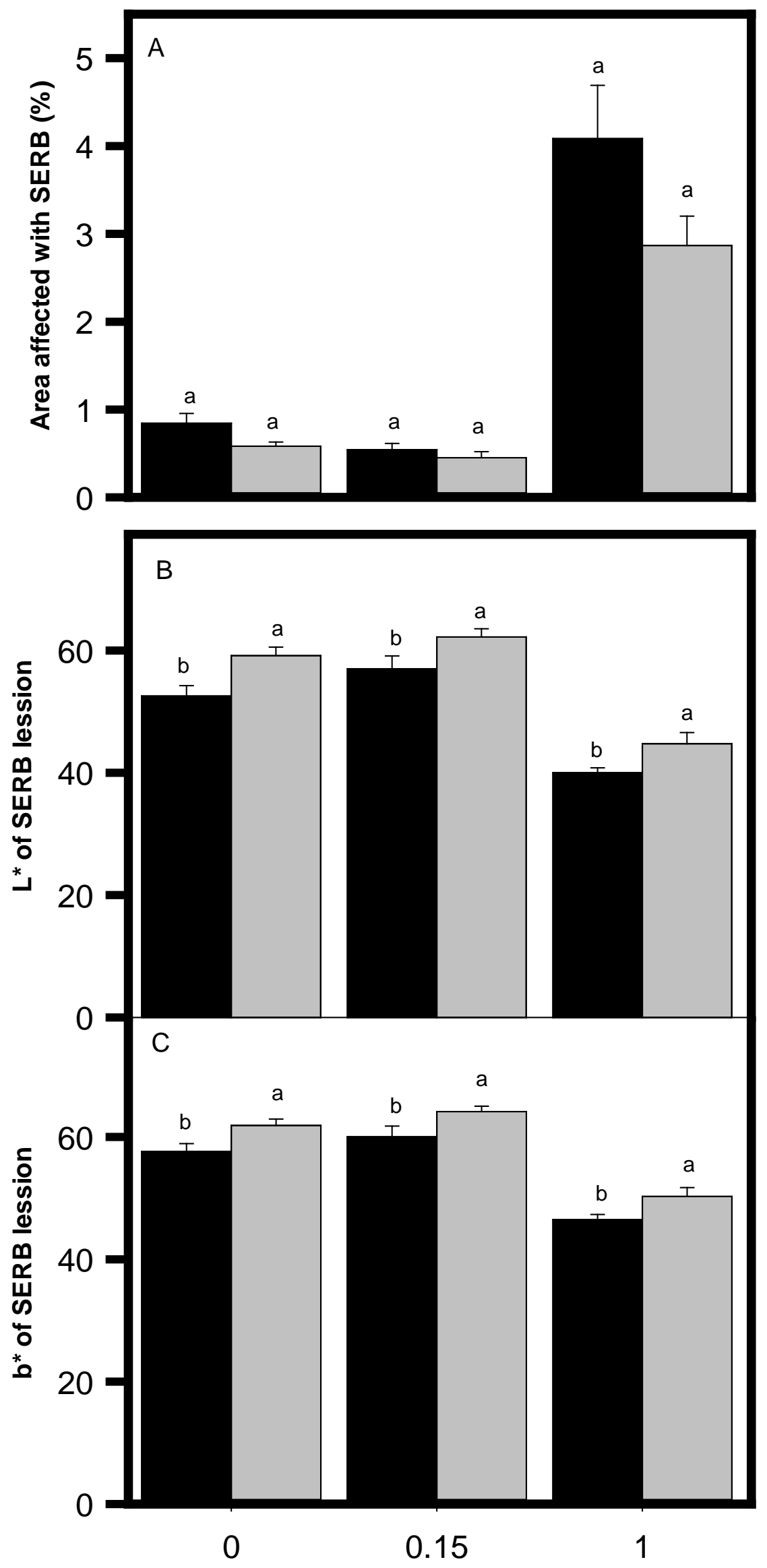

Fig 1. 


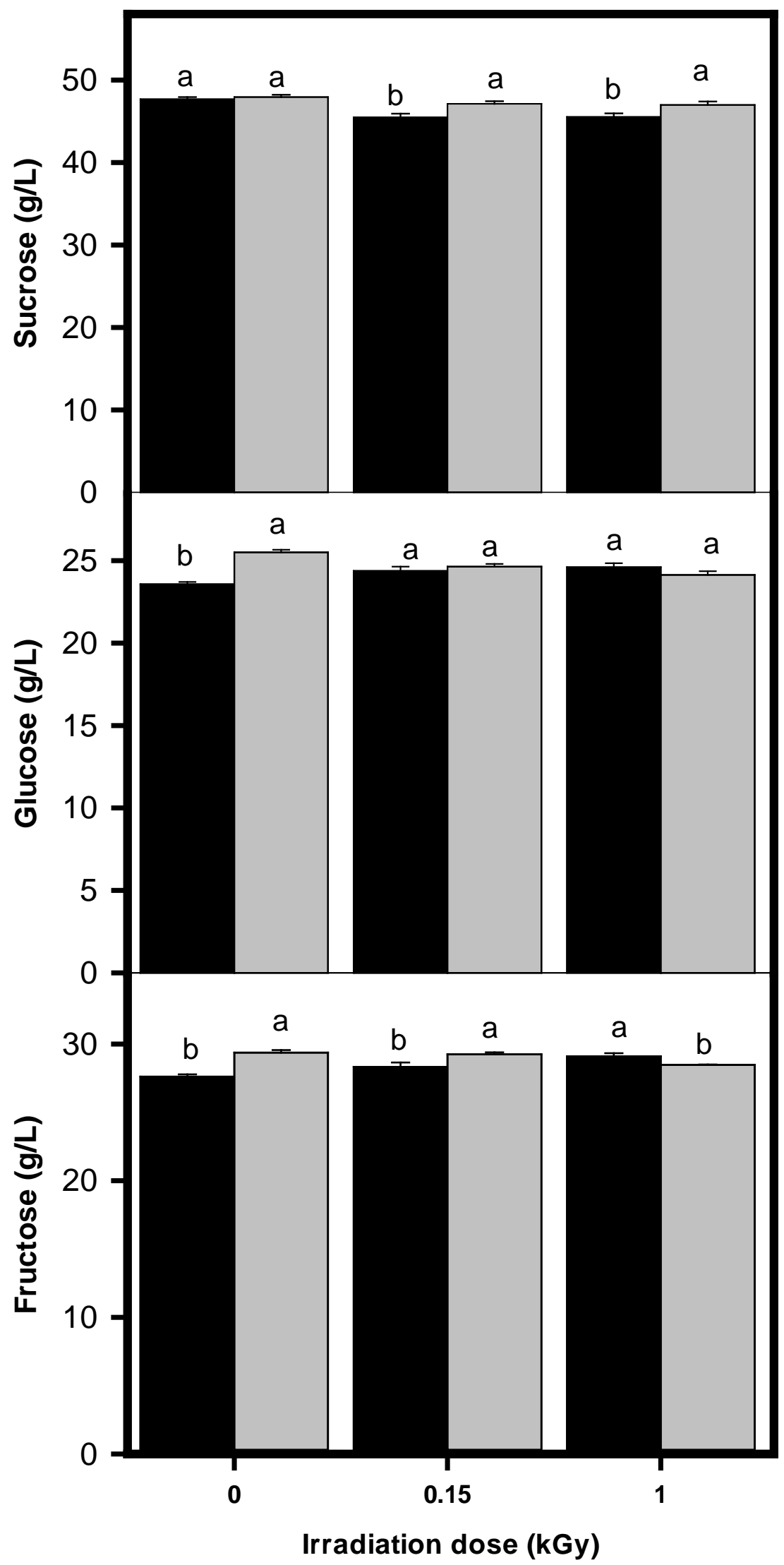




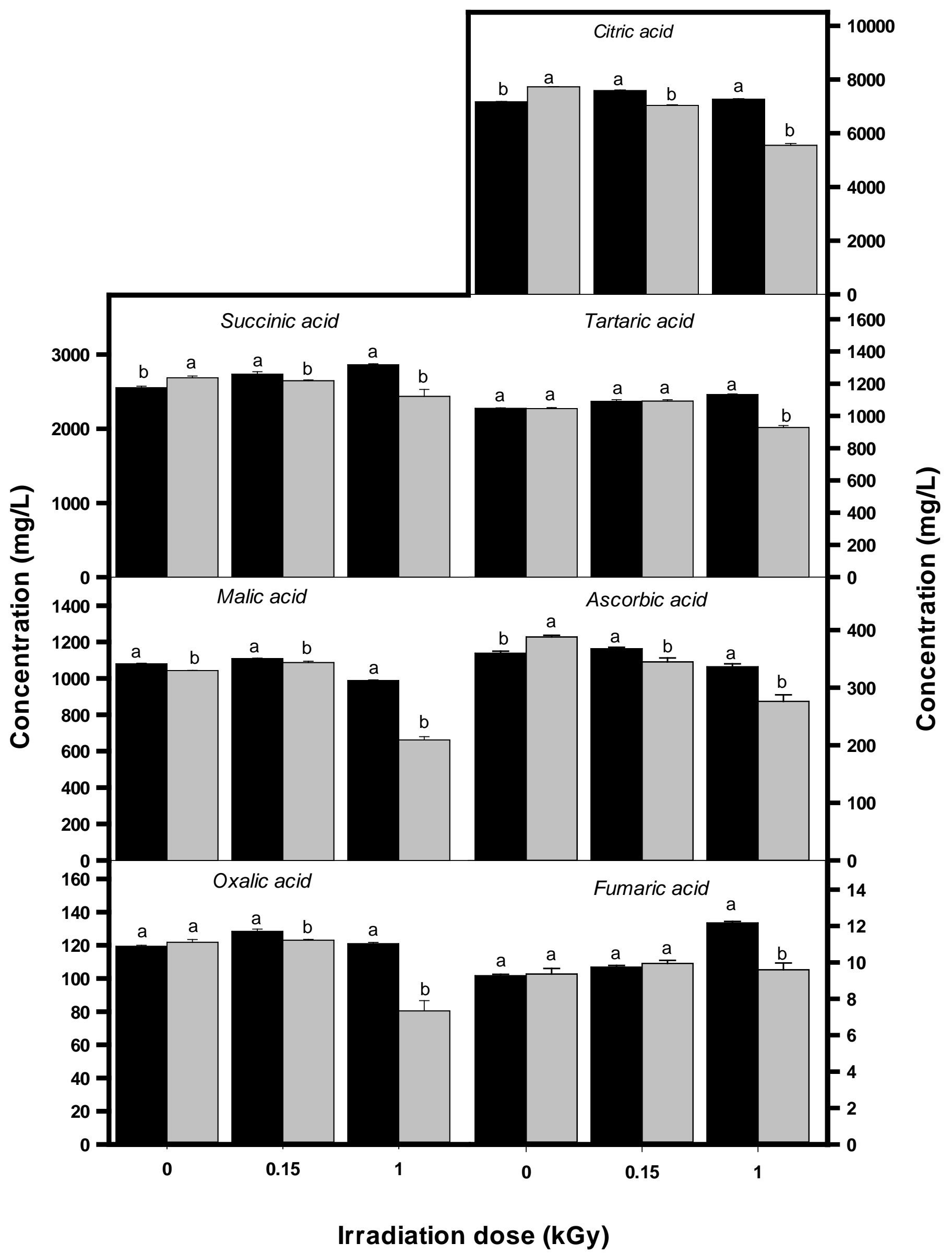

Fig. 3 


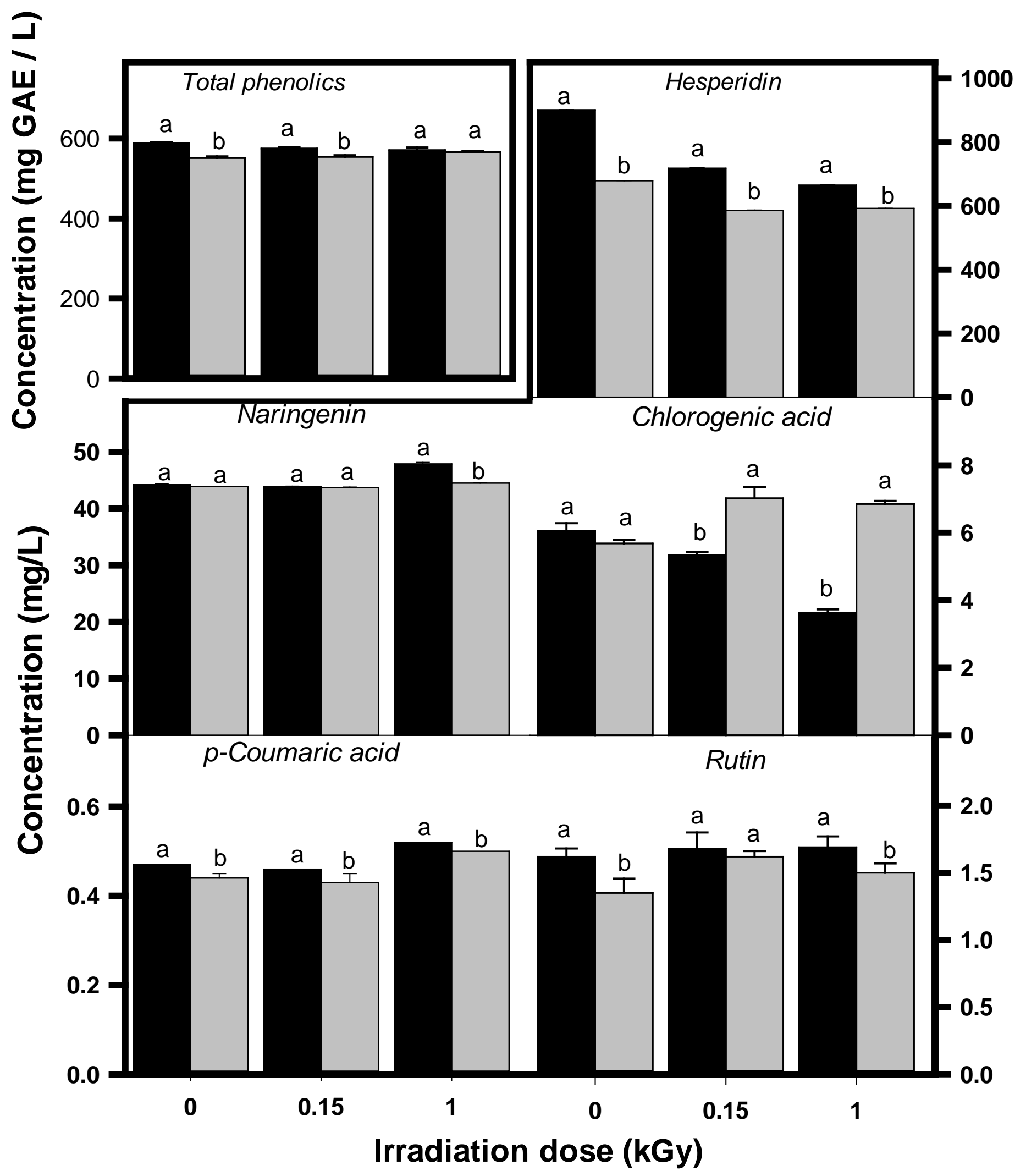

Fig. 4 